\title{
DWT Analysis of Scatter-Ray Due to the Changed Energy on Digital Medical Images
}

\author{
Jisun Kim*, Jaeeun Jung**, Byeoungju Ahn* \\ Dept. of Radiology, Nambu University, Department of Radiological Science, Daegu Health College**

\section{디지털 의료영상에서 에너지 변화에 따른 산란선의 DWT 분석} \\ 김지선*, 정재은**, 안병주* \\ 남부대학교 방사선학과*, 대구보건대학교 방사선과**
}

\begin{abstract}
This study extracts characteristics of signal by wavelet transform to prove that the Compton scattering, occurred by changed the energy, influenced a picture. We also analyzed the extracted data and evaluated how much the picture of scatter-rays was affected by a change of tube voltage. For this study, we wrote a program with MatLap which is engineering tool and evaluated with the program on variation of scattered-rays due to increased tube voltage. The evaluation result shows both $\mathrm{CR}$ and $\mathrm{DR}$ have frequency changes of high frequency area by tube voltage variations and it proved that Compton scattering influences the picture. In conclusion, according to this study indicates that DR is more sensitive to radiation with high energy than CR. Therefore, the research on DR detector needs to be advanced as actual condition of clinical setting is being changed to DR circumstance gradually. From the result of this study, we expect that assessment method of the image quality using MatLab Tool becomes the official assessment method and very useful method.
\end{abstract}

중심단어 : Changed Energy, Scatter Ray, CR, DR, DWT

\section{요 약}

본 연구에서는 에너지 변화에 의하여 발생하는 콤프턴 산란이 화질에 영향을 미친다는 것을 증명하기 위하여 웨이 브릿 변환으로 신호의 특성을 추출하였다. 추출된 데이터를 분석하여 에너지의 변화에 따른 산란선의 화질영향 정도를 평가하고자 하였다. 이를 위하여 공학용 도구인 MatLab Tool을 이용하여 프로그램을 작성하였고, 작성된 프로그램을 이용하여 관전압 증가에 따른 산란선의 변화를 평가하였다. 평가결과 $\mathrm{CR}$ 과 $\mathrm{DR}$ 모두 관전압 변화에 따라서 고주파영역 의 주파수 변화가 있는 것으로 보아 콤프턴 산란선의 영향이 있는 것으로 나타났다. 급격한 주파수의 변화가 나타나는 관전압 영역이 $\mathrm{CR}$ 은 $80 \mathrm{kVp}, \mathrm{DR}$ 은 $90 \mathrm{kVp}$ 로 나타난 것으로 보아 $\mathrm{DR}$ 의 검출기는 에너지에 대한 민감도가 낮은 것으 로 알 수 있다. 결론적으로 본 연구의 결과로 보아 $\mathrm{CR}$ 보다는 $\mathrm{DR}$ 이 에너지가 높은 방사선에 민감한 것으로 나타났다. 본 연구의 결과는 공학용 도구인 MatLab Tool을 이용한 영상의 화질평가 방법이 공식적인 화질평가의 방법으로 인정 되어 유용하게 적용될 것을 기대한다.

중심단어 : 에너지변화, 산란선, $\mathrm{CR}, \mathrm{DR}, \mathrm{DWT}$ 


\section{I. 서론}

현대의학에 있어서 방사선의 의학적 이용은 인간의 질병 진단과 치료 및 연구에 활용되어 질병으로부터 건강을 보호하고 의학을 발전시키는데 중요한 역할을 해왔다 ${ }^{[1][2][3]}$. 방사선이 물질에 조사되면 방사선과 물 질과의 상호작용, 즉 입사 광자가 원자의 궤도 전자와 충돌하면서 원자의 궤도 전자를 이탈시키는 현상인 전리작용에 의하여 원자는 이온화되게 된다. 방사선과 물질과의 상호작용으로는 광전효과, Compton 산란, 전 자쌍생성이 일어난다. 이 중 Compton 산란이란, 입사 광자가 궤도 전자와 충돌하면서 광자의 에너지와 운 동량 중 일부를 충돌하는 전자에 전달하고, 입사 광자 는 에너지를 잃게 되어 파장이 길어지면서 그 진행 경 로를 바꾸어 산란되어 진행하게 된다. 이와 같이 에너 지를 잃고 방향을 바꾸어 진행하는 광자를 산란선이 라고 하며, 궤도에 있던 전자는 입사 광자의 에너지와 운동량을 받아 되튀는데 이 전자를 되튐전자 또는 Compton 전자라고 한다 ${ }^{[4]}$. 또한 전자쌍생성이란 입 사 광자가 물질을 구성하는 원자핵의 쿨롱장 내에 서 상호 작용하여 광자 자체가 소멸하고 전자와 양전 자의 한 쌍이 생성되는 현상이다. 입사 광자가 전자 와 양전자를 생성하기 위해서는 적어도 전자의 정 지 질량 에너지인 $0.511 \mathrm{MeV}$ 의 2배인 $1.022 \mathrm{MeV}$ 이상 의 에너지가 필요하다 ${ }^{[5]}$. 방사선과 물질과의 상호작용 이 원자에 입사한 광자는 궤도전자를 원자를 이온화 시켜 자유전자를 방출하며, 입사한 광자 자신은 사라 지는데, 이것을 광전효과라 한다. ${ }^{[5] . ~ ㅇ ㅕ ㅇ ㅅ ㅏ ㅇ ㅇ ㅢ ~ ㅍ ㅜ ㅁ ㅈ ㅣ ㄹ ㅇ ㅡ ㄹ ~ ㅎ ㅘ ㄱ ~}$ 인하는 방법으로 물리적 평가방법과 심리적 평가방법 이 있으며, 물리적 평가방법은 특성곡선(H-D Curve), MTF (Modulation Transfer Function: 변조전달함수) ${ }^{[7]}$, 잡음력스펙트럼(noise power spectrum; NPS) ${ }^{[8]}$, 양자검 출효율(detective quantum efficiency; DQE) ${ }^{[9]}$, RMS(Root Mean Square), 위너 스펙트럼(Wiener spectrum), Entropy 등이 있다. 또한 공학용 도구인 DWT(Discrete Wavelet Transform)는 신호를 공간영역에서 주파수 영역으로 바꾼다 ${ }^{[10]}$. 이에 본 연구에서는 관전압의 증가에 의하 여 발생하는 Compton 산란이 화질에 영향을 미친다는 가설을 증명하기 위하여 웨이브렛 변환으로 신호의 특성을 추출하고, 추출된 데이터를 분석하여 관전압의
변화에 따른 산란선의 화질영향 정도를 평가하고자 한다. 이를 위하여 공학용 도구인 MatLab Tool을 이용 하여 프로그램을 작성하였고 작성된 프로그램이 영상 의 화질평가 도구로서 유용한가를 입증하고자 한다.

\section{II. 실험 기기 및 방법}

\section{1. 실험}

본 연구를 위하여 실험에서 $\mathrm{CR}$ 장비는 $\mathrm{ADC}$ Compact plus digitizer, AGFA 이며, DR 장비는 Philips Digital-Diagnost OPTIMUS50를 이용하였다. 이용한 검출 기로는 $\mathrm{DR}$ 은 평판형 검출기 $\left(43^{*} 43 \mathrm{~cm}\right), \mathrm{CR}$ 영상판은 Image Plate $\left(6\right.$ pixels $/ \mathrm{mm}$ (Cassette sizes $36^{*} 43 \mathrm{~cm}$ )를 이용하 였고, 주파수 분석은 Matlab R 20을 활용하여 분석하였 다.

\section{2. 영상획득}

실험에 필요한 영상을 획득하기 위하여 아크릴 판 위에 크기가 각각 다르게 구멍을 파고 파라핀과 황산 바륨 $\left(\mathrm{BaSO}_{4}\right)$ 으로 구멍을 채워 놓았다. 파라핀과 황산 바륨을 각각의 열에 채워 놓은 이유는 방사선 투과성 물질과 광전효과를 많이 유발하는 조영제인 황산바륨 이 Compton 산란에 어떠한 영향을 미치는가를 보고자 하였다. 영상획득 과정은 Fig. 1와 같이 만들어진 실험 재료를 이용하여 Fig. 2처럼 $\mathrm{CR}$ 과 DR 장비를 이용하 였으며, 거리는 40 inch로 고정하고, $100 \mathrm{~mA}$ 에 $0.6 \mathrm{sec}$ 를 즉, $60 \mathrm{mAs}$ 의 조건으로 촬영하였으며, 관전압을 60 $\mathrm{kVp}$ 에서부터 $100 \mathrm{kVp}$ 까지 바꾸어 가며 각각 5 회씩 촬 영하였다.

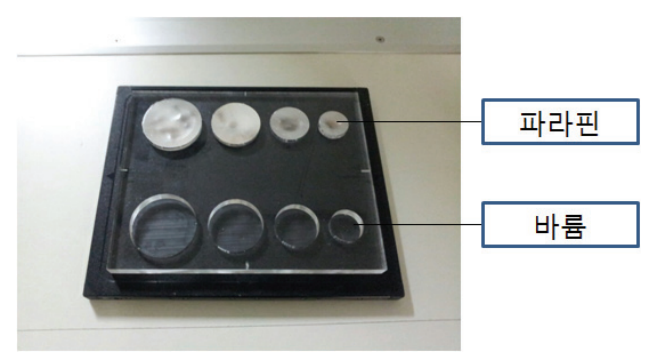

Fig. 1. Experimental Material. 


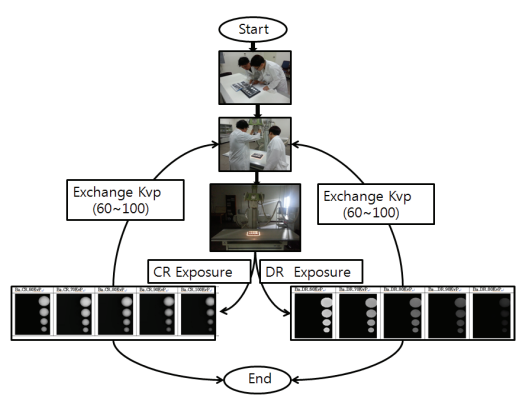

Fig. 2. Procedure of Experiment.

Fig. 2의 절차에 의하여 획득된 영상은 아래의 Table 1 와 Table 2에 나타내었다.

Table 1. CR Images
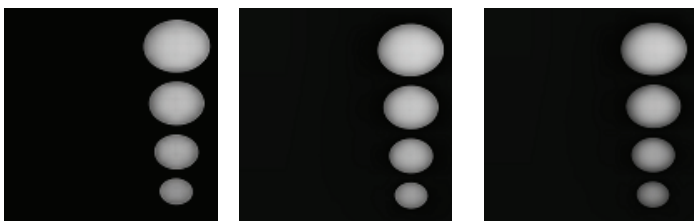

(a) Ba CR 60kVp

(b) Ba CR 70kVp

(c) Ba CR $80 \mathrm{kVp}$
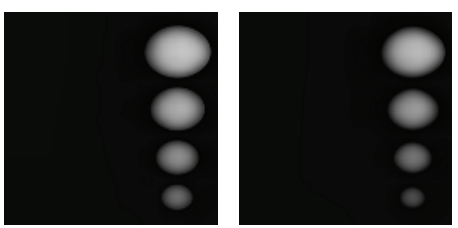

(d) Ba CR $90 \mathrm{kVp}$

(e) Ba CR $100 \mathrm{kVp}$

Table 2. DR Images
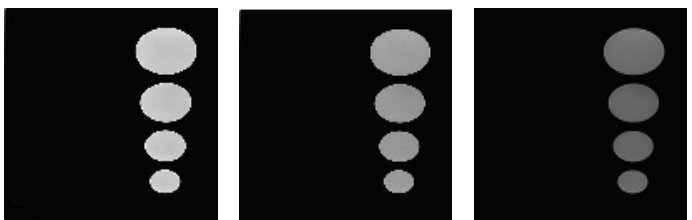

(a) Ba DR $60 \mathrm{kVp}$

(b) Ba DR 70kVp

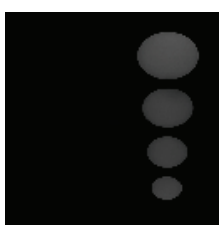

(d) Ba DR 90kVp

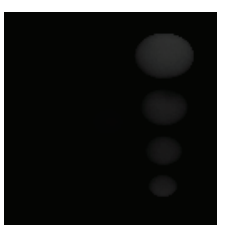

(d) Ba DR 100kVp

\section{3. 획득된 영상의 Wavelet 변환}

Table 1과 Table 2처럼 획득된 영상을 Fig. 3과 같은 절차로 Matlab M-programing을 하여 3단계 웨이브렛 분 해를 하였다.

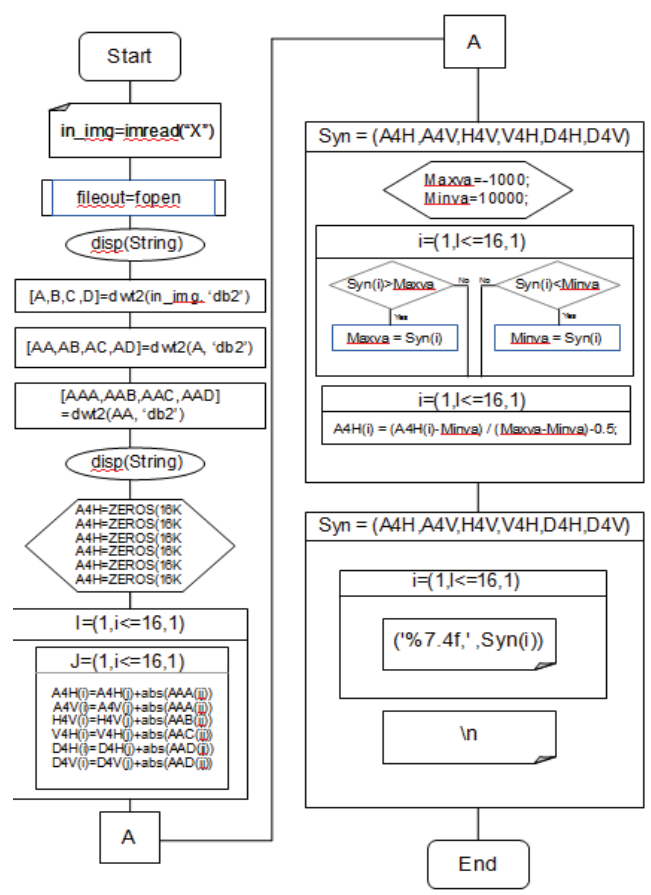

Fig. 3. Flow chart of Matlab M-programming.

Wavelet 분해결과 Table 3와 같이 CR과 $\mathrm{DR}$ 각각 $\mathrm{kVp}$ 변화에 따른 원래 영상과 1 레벨부터 3 레벨까지의 분해된 영상을 나타내었다. 
Table 3. Result of DWT

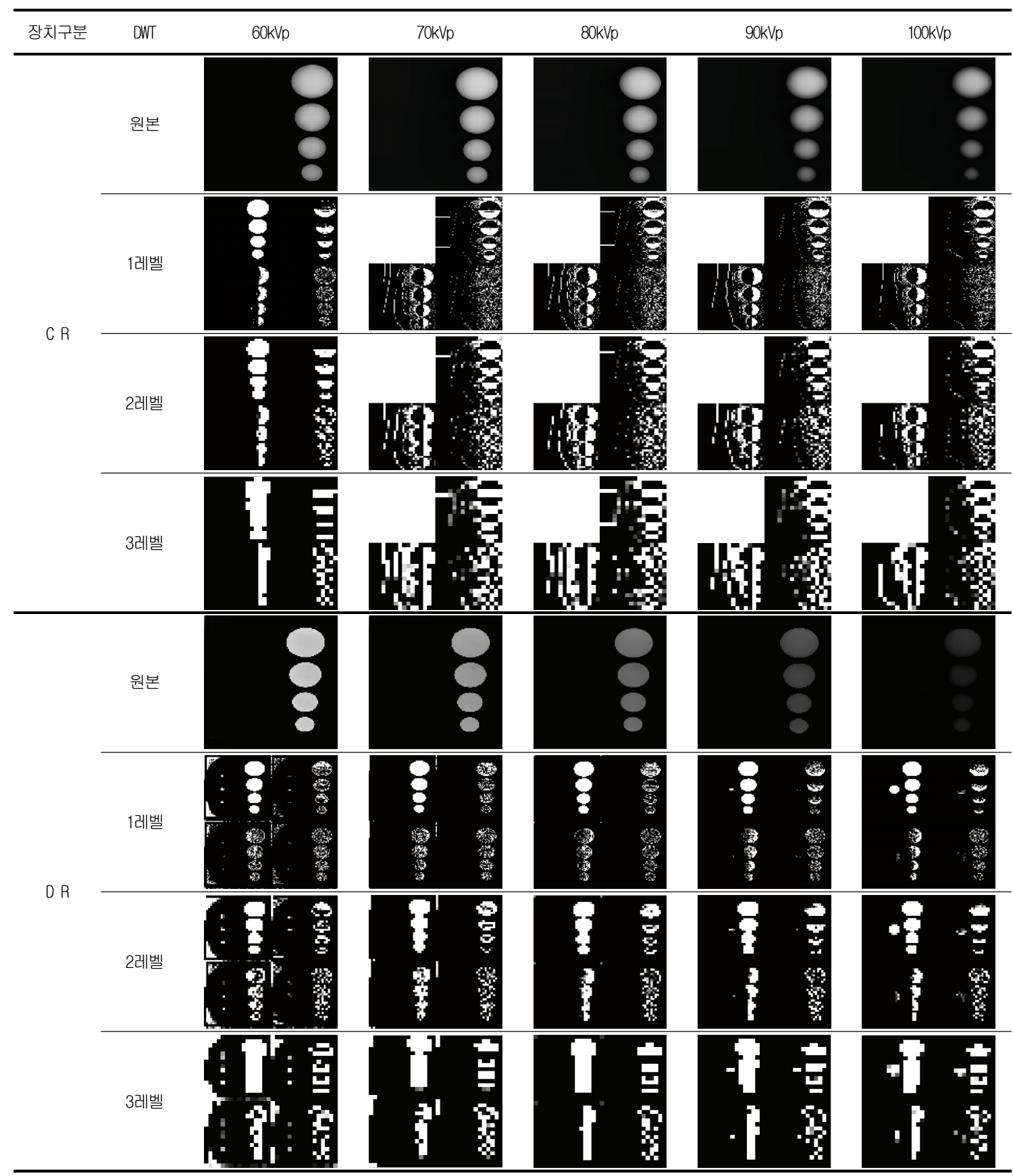

1.3 Wavelet 변환된 데이터

른 3레벨 분해 영상에서 저주파 영영의 특징을 나타내 는 것이다.

Table 4부터 Table 13은 CR과 DR의 $\mathrm{kVp}$ 변화에 따 
Table 4. A feature value of low frequency area that is after 3-level DWT on CR_60 kVp Image

\begin{tabular}{|c|c|c|c|c|c|c|c|c|c|c|c|c|c|c|c|c|}
\hline A4H & -0.50 & -0.50 & -0.50 & -0.50 & -0.50 & -0.50 & -0.50 & -0.50 & -0.50 & -0.50 & -0.42 & 0.05 & 0.50 & 0.47 & -0.03 & -0.45 \\
\hline A4V & -0.48 & 0.11 & 0.50 & 0.46 & -0.06 & -0.35 & 0.19 & 0.25 & -0.16 & -0.36 & 0.04 & -0.07 & -0.45 & -0.15 & -0.30 & -0.50 \\
\hline $\mathrm{H} 4 \mathrm{H}$ & -0.41 & 0.07 & 0.50 & 0.37 & 0.04 & -0.24 & 0.13 & 0.00 & 0.05 & -0.26 & 0.35 & 0.18 & -0.28 & -0.04 & -0.18 & -0.50 \\
\hline $\mathrm{H} 4 \mathrm{~V}$ & -0.50 & -0.50 & -0.50 & -0.50 & -0.50 & -0.50 & -0.50 & -0.50 & -0.50 & -0.50 & -0.37 & 0.27 & 0.49 & 0.50 & 0.19 & -0.41 \\
\hline $\mathrm{D} 4 \mathrm{H}$ & -0.50 & -0.50 & -0.50 & -0.50 & -0.50 & -0.50 & -0.50 & -0.50 & -0.50 & -0.50 & -0.22 & 0.42 & -0.14 & 0.02 & 0.50 & -0.26 \\
\hline D4V & -0.24 & 0.22 & -0.21 & 0.21 & 0.35 & 0.24 & 0.12 & -0.15 & 0.50 & 0.19 & -0.20 & 0.30 & -0.40 & 0.06 & -0.01 & -0.50 \\
\hline
\end{tabular}

Table 5. A feature value of low frequency area that is after 3-level DWT on CR_70 kVp Image

\begin{tabular}{|c|c|c|c|c|c|c|c|c|c|c|c|c|c|c|c|c|}
\hline A4H & -0.47 & -0.47 & -0.47 & -0.47 & -0.47 & -0.48 & -0.48 & -0.49 & -0.49 & -0.50 & -0.44 & 0.03 & 0.50 & 0.47 & -0.04 & -0.47 \\
\hline A4V & -0.49 & -0.14 & 0.43 & 0.50 & 0.13 & -0.46 & 0.04 & 0.26 & 0.00 & -0.47 & -0.06 & 0.00 & -0.41 & -0.26 & -0.21 & -0.50 \\
\hline $\mathrm{H} 4 \mathrm{H}$ & -0.50 & -0.02 & 0.33 & 0.50 & 0.10 & -0.32 & 0.17 & -0.02 & 0.14 & -0.33 & 0.24 & 0.36 & -0.36 & -0.14 & -0.10 & -0.48 \\
\hline $\mathrm{H} 4 \mathrm{~V}$ & -0.50 & -0.50 & -0.50 & -0.50 & -0.50 & -0.50 & -0.50 & -0.50 & -0.50 & -0.49 & -0.34 & 0.46 & 0.43 & 0.50 & 0.40 & -0.37 \\
\hline $\mathrm{D} 4 \mathrm{H}$ & -0.50 & -0.50 & -0.50 & -0.50 & -0.50 & -0.50 & -0.49 & -0.49 & -0.49 & -0.49 & -0.19 & 0.35 & -0.09 & 0.07 & 0.50 & -0.14 \\
\hline D4V & -0.50 & 0.50 & 0.39 & -0.19 & 0.21 & -0.42 & -0.13 & -0.46 & -0.09 & -0.40 & 0.30 & -0.25 & 0.04 & 0.16 & 0.28 & -0.39 \\
\hline
\end{tabular}

Table 6. A feature value of low frequency area that is after 3-level DWT on CR_80 kVp Image

\begin{tabular}{|c|c|c|c|c|c|c|c|c|c|c|c|c|c|c|c|c|}
\hline $\mathrm{A} 4 \mathrm{H}$ & -0.46 & -0.46 & -0.46 & -0.47 & -0.47 & -0.47 & -0.48 & -0.48 & -0.49 & -0.50 & -0.42 & 0.08 & 0.50 & 0.36 & -0.17 & -0.49 \\
\hline $\mathrm{A} 4 \mathrm{~V}$ & -0.49 & -0.13 & 0.45 & 0.50 & 0.04 & -0.47 & 0.03 & 0.24 & -0.08 & -0.47 & -0.08 & -0.07 & -0.46 & -0.28 & -0.28 & -0.50 \\
\hline $\mathrm{H} 4 \mathrm{H}$ & -0.49 & 0.12 & 0.48 & 0.50 & 0.31 & -0.35 & 0.31 & 0.45 & 0.19 & -0.40 & 0.21 & 0.20 & -0.38 & 0.06 & 0.06 & -0.50 \\
\hline $\mathrm{H} 4 \mathrm{~V}$ & -0.50 & -0.50 & -0.50 & -0.50 & -0.50 & -0.50 & -0.50 & -0.50 & -0.49 & -0.49 & -0.33 & 0.42 & 0.46 & 0.50 & 0.12 & -0.41 \\
\hline $\mathrm{D} 4 \mathrm{H}$ & -0.50 & -0.50 & -0.50 & -0.49 & -0.50 & -0.50 & -0.49 & -0.50 & -0.49 & -0.49 & -0.22 & 0.12 & -0.31 & 0.03 & 0.50 & -0.29 \\
\hline D4V & -0.50 & 0.35 & 0.00 & -0.14 & 0.50 & -0.23 & 0.33 & -0.43 & 0.23 & -0.24 & -0.02 & -0.07 & -0.12 & 0.00 & -0.03 & -0.48 \\
\hline
\end{tabular}

Table 7. A feature value of low frequency area that is after 3-level DWT on CR_90 kVp Image

\begin{tabular}{|c|c|c|c|c|c|c|c|c|c|c|c|c|c|c|c|c|}
\hline $\mathrm{A} 4 \mathrm{H}$ & -0.47 & -0.47 & -0.47 & -0.47 & -0.48 & -0.48 & -0.48 & -0.49 & -0.49 & -0.50 & -0.49 & -0.09 & 0.49 & 0.50 & -0.05 & -0.47 \\
\hline A4V & -0.50 & -0.10 & 0.50 & 0.50 & -0.09 & -0.46 & 0.02 & 0.20 & -0.22 & -0.47 & -0.12 & -0.17 & -0.49 & -0.32 & -0.37 & -0.50 \\
\hline $\mathrm{H} 4 \mathrm{H}$ & -0.48 & 0.10 & 0.50 & 0.49 & 0.11 & -0.40 & 0.28 & 0.24 & 0.05 & -0.39 & 0.21 & 0.12 & -0.45 & -0.15 & -0.23 & -0.50 \\
\hline H4V & -0.50 & -0.50 & -0.50 & -0.50 & -0.50 & -0.50 & -0.50 & -0.50 & -0.50 & -0.49 & -0.43 & 0.09 & 0.48 & 0.50 & 0.14 & -0.40 \\
\hline $\mathrm{D} 4 \mathrm{H}$ & -0.50 & -0.50 & -0.50 & -0.50 & -0.50 & -0.50 & -0.49 & -0.49 & -0.49 & -0.49 & -0.25 & 0.48 & -0.09 & -0.01 & 0.50 & -0.13 \\
\hline D4V & -0.49 & 0.29 & 0.29 & 0.30 & 0.36 & -0.12 & -0.10 & -0.38 & 0.50 & -0.13 & 0.15 & 0.32 & -0.28 & -0.31 & -0.30 & -0.50 \\
\hline
\end{tabular}

Table 8. A feature value of low frequency area that is after 3-level DWT on CR_100 kVp Image

\begin{tabular}{|c|c|c|c|c|c|c|c|c|c|c|c|c|c|c|c|c|}
\hline $\mathrm{A} 4 \mathrm{H}$ & -0.46 & -0.46 & -0.46 & -0.46 & -0.47 & -0.48 & -0.48 & -0.48 & -0.49 & -0.49 & -0.50 & -0.19 & 0.41 & 0.50 & -0.05 & -0.47 \\
\hline A4V & -0.50 & -0.18 & 0.48 & 0.50 & -0.14 & -0.49 & -0.08 & 0.15 & -0.28 & -0.49 & -0.21 & -0.24 & -0.49 & -0.40 & -0.42 & -0.48 \\
\hline $\mathrm{H} 4 \mathrm{H}$ & -0.49 & 0.08 & 0.49 & 0.50 & 0.10 & -0.43 & 0.26 & 0.42 & -0.02 & -0.44 & 0.02 & -0.02 & -0.49 & -0.19 & -0.25 & -0.50 \\
\hline $\mathrm{H} 4 \mathrm{~V}$ & -0.50 & -0.50 & -0.50 & -0.50 & -0.50 & -0.50 & -0.50 & -0.50 & -0.50 & -0.49 & -0.45 & -0.08 & 0.44 & 0.50 & 0.08 & -0.40 \\
\hline $\mathrm{D} 4 \mathrm{H}$ & -0.50 & -0.50 & -0.50 & -0.50 & -0.50 & -0.50 & -0.49 & -0.49 & -0.48 & -0.48 & -0.35 & 0.43 & -0.05 & -0.06 & 0.50 & -0.15 \\
\hline D4V & -0.48 & 0.50 & 0.29 & 0.18 & 0.44 & -0.23 & 0.43 & -0.46 & 0.37 & -0.32 & 0.13 & 0.11 & -0.45 & -0.15 & 0.01 & -0.50 \\
\hline
\end{tabular}


"DWT Analysis of Scatter-Ray Due to the Changed Energy on Digital Medical Images"

Table 9. A feature value of low frequency area that is after 3-level DWT on DR_60 kVp Image

\begin{tabular}{|c|c|c|c|c|c|c|c|c|c|c|c|c|c|c|c|c|}
\hline A4H & -0.48 & -0.50 & -0.50 & -0.50 & -0.50 & -0.50 & -0.50 & -0.50 & -0.50 & -0.48 & -0.04 & 0.48 & 0.50 & 0.06 & -0.44 & -0.50 \\
\hline A4V & -0.49 & -0.21 & 0.45 & 0.50 & 0.19 & -0.36 & 0.26 & 0.31 & -0.22 & -0.11 & 0.17 & -0.28 & -0.15 & -0.11 & -0.50 & -0.50 \\
\hline $\mathrm{HAH}$ & -0.45 & -0.13 & -0.08 & 0.06 & 0.00 & -0.33 & 0.05 & -0.08 & -0.15 & -0.04 & 0.50 & -0.27 & -0.14 & -0.18 & -0.49 & -0.50 \\
\hline HAV & -0.49 & -0.49 & -0.49 & -0.50 & -0.50 & -0.50 & -0.50 & -0.50 & -0.50 & -0.47 & -0.07 & 0.50 & 0.49 & 0.04 & -0.43 & -0.50 \\
\hline $\mathrm{D} 4 \mathrm{H}$ & -0.47 & -0.50 & -0.50 & -0.50 & -0.50 & -0.50 & -0.50 & -0.50 & -0.50 & -0.44 & 0.16 & 0.06 & -0.12 & 0.50 & -0.33 & -0.50 \\
\hline D4V & -0.46 & 0.25 & 0.20 & -0.34 & 0.09 & -0.12 & 0.04 & 0.00 & 0.12 & 0.50 & -0.28 & 0.00 & 0.23 & 0.22 & -0.50 & -0.48 \\
\hline
\end{tabular}

Table 10. A feature value of low frequency area that is after 3-level DWT on DR_70 kVp Image

\begin{tabular}{|c|c|c|c|c|c|c|c|c|c|c|c|c|c|c|c|c|}
\hline A4H & -0.49 & -0.50 & -0.50 & -0.50 & -0.50 & -0.50 & -0.50 & -0.50 & -0.50 & -0.49 & -0.04 & 0.49 & 0.50 & 0.03 & -0.45 & -0.50 \\
\hline A4V & 0.23 & -0.30 & 0.40 & 0.50 & 0.24 & -0.39 & 0.17 & 0.28 & -0.16 & -0.21 & 0.13 & -0.22 & -0.23 & -0.07 & -0.50 & -0.50 \\
\hline $\mathrm{H} 4 \mathrm{H}$ & -0.44 & -0.23 & -0.05 & 0.05 & -0.06 & -0.26 & 0.09 & -0.12 & -0.06 & -0.20 & 0.50 & -0.18 & -0.21 & -0.12 & -0.50 & -0.50 \\
\hline HAV & -0.49 & -0.50 & -0.50 & -0.50 & -0.50 & -0.50 & -0.50 & -0.50 & -0.50 & -0.48 & 0.01 & 0.50 & 0.50 & 0.03 & -0.41 & -0.50 \\
\hline D4H & -0.48 & -0.50 & -0.50 & -0.50 & -0.50 & -0.50 & -0.50 & -0.50 & -0.50 & -0.46 & 0.18 & -0.07 & -0.13 & 0.50 & -0.29 & -0.50 \\
\hline D4V & -0.49 & 0.06 & 0.41 & -0.37 & 0.10 & -0.45 & -0.24 & -0.15 & 0.50 & 0.10 & -0.47 & 0.11 & -0.05 & 0.35 & -0.50 & -0.50 \\
\hline
\end{tabular}

Table 11. A feature value of low frequency area that is after 3-level DWT on DR_80 kVp Image

\begin{tabular}{|c|c|c|c|c|c|c|c|c|c|c|c|c|c|c|c|c|}
\hline A4H & -0.50 & -0.50 & -0.50 & -0.50 & -0.50 & -0.50 & -0.50 & -0.50 & -0.50 & -0.47 & 0.01 & 0.50 & 0.47 & -0.03 & -0.46 & -0.50 \\
\hline A4V & -0.50 & -0.25 & 0.43 & 0.50 & 0.17 & -0.39 & 0.16 & 0.23 & -0.24 & -0.18 & 0.09 & -0.29 & -0.20 & -0.14 & -0.50 & -0.50 \\
\hline $\mathrm{HAH}$ & -0.50 & -0.11 & -0.03 & 0.13 & 0.00 & -0.34 & 0.12 & -0.04 & -0.12 & -0.05 & 0.50 & -0.23 & -0.17 & -0.12 & -0.50 & -0.50 \\
\hline HAV & -0.50 & -0.50 & -0.50 & -0.50 & -0.50 & -0.50 & -0.50 & -0.50 & -0.50 & -0.45 & 0.00 & 0.46 & 0.50 & -0.09 & -0.44 & -0.50 \\
\hline $\mathrm{D} 4 \mathrm{H}$ & -0.50 & -0.50 & -0.50 & -0.50 & -0.50 & -0.50 & -0.50 & -0.50 & -0.50 & -0.37 & 0.50 & -0.06 & 0.01 & 0.29 & -0.32 & -0.50 \\
\hline D4V & -0.50 & 0.40 & 0.49 & -0.26 & 0.03 & -0.24 & 0.02 & -0.06 & 0.19 & 0.50 & -0.41 & -0.04 & 0.12 & 0.33 & -0.50 & -0.50 \\
\hline
\end{tabular}

Table 12. A feature value of low frequency area that is after 3-level DWT on DR_90 kVp Image

\begin{tabular}{|c|c|c|c|c|c|c|c|c|c|c|c|c|c|c|c|c|}
\hline $\mathrm{A} 4 \mathrm{H}$ & -0.50 & -0.50 & -0.50 & -0.50 & -0.50 & -0.50 & -0.50 & -0.50 & -0.50 & -0.49 & -0.13 & 0.44 & 0.50 & 0.07 & -0.42 & -0.50 \\
\hline A4V & -0.50 & -0.23 & 0.45 & 0.50 & 0.12 & -0.43 & 0.09 & 0.17 & -0.27 & -0.25 & 0.03 & -0.30 & -0.27 & -0.14 & -0.50 & -0.50 \\
\hline $\mathrm{HAH}$ & -0.50 & 0.02 & 0.34 & 0.46 & 0.28 & -0.37 & 0.23 & 0.19 & -0.05 & 0.02 & 0.50 & -0.09 & -0.08 & 0.07 & -0.50 & -0.50 \\
\hline HAV & -0.50 & -0.50 & -0.50 & -0.50 & -0.50 & -0.50 & -0.50 & -0.50 & -0.50 & -0.48 & -0.15 & 0.48 & 0.50 & 0.04 & -0.38 & -0.50 \\
\hline $\mathrm{D} 4 \mathrm{H}$ & -0.50 & -0.50 & -0.50 & -0.50 & -0.50 & -0.50 & -0.50 & -0.50 & -0.50 & -0.44 & 0.04 & -0.03 & -0.15 & 0.50 & -0.19 & -0.50 \\
\hline D4V & -0.50 & 0.50 & 0.46 & -0.11 & 0.40 & -0.25 & -0.11 & -0.12 & 0.16 & 0.25 & -0.42 & 0.00 & -0.13 & 0.40 & -0.50 & -0.50 \\
\hline
\end{tabular}

Table 13. A feature value of low frequency area that is after 3-level DWT on DR_100 kVp Image

\begin{tabular}{|c|c|c|c|c|c|c|c|c|c|c|c|c|c|c|c|c|}
\hline A4H & -0.50 & -0.50 & -0.50 & -0.50 & -0.50 & -0.50 & -0.50 & -0.49 & -0.49 & -0.49 & -0.13 & 0.49 & 0.50 & -0.02 & -0.47 & -0.50 \\
\hline A4V & -0.50 & -0.31 & 0.45 & 0.50 & 0.05 & -0.48 & -0.12 & 0.00 & -0.36 & -0.36 & -0.15 & -0.40 & -0.35 & -0.26 & -0.50 & -0.50 \\
\hline $\mathrm{H} 4 \mathrm{H}$ & -0.50 & -0.11 & 0.50 & 0.36 & 0.35 & -0.43 & 0.26 & 0.47 & -0.18 & -0.19 & 0.18 & -0.22 & -0.11 & 0.03 & -0.50 & -0.50 \\
\hline H4V & -0.50 & -0.50 & -0.50 & -0.50 & -0.50 & -0.50 & -0.50 & -0.49 & -0.49 & -0.48 & -0.14 & 0.44 & 0.50 & -0.08 & -0.45 & -0.50 \\
\hline D4H & -0.50 & -0.50 & -0.50 & -0.50 & -0.50 & -0.50 & -0.49 & -0.48 & -0.49 & -0.38 & 0.50 & 0.35 & 0.30 & 0.44 & -0.24 & -0.50 \\
\hline D4V & -0.50 & 0.14 & 0.50 & -0.24 & -0.09 & -0.38 & -0.16 & -0.38 & -0.04 & -0.31 & -0.44 & -0.05 & -0.39 & -0.09 & -0.50 & -0.50 \\
\hline
\end{tabular}


"J. Korean. Soc. Radiol., Vol. 8, No. 2, February 2014"

\section{III. 연구결과}

실험 결과 Table 4 부터 Table 13 까지의 결과를 얻을 수 있었다. 얻어진 결과에서 각각의 파라미터의 의미 는 아래의 Table 14와 같다.

Table 14. Feature parameters

\begin{tabular}{cc}
\hline 파라미터 & 의 미 \\
\hline$A 4 H$ & 저주파 계수 행렬의 특징 파라미터(수평방향) \\
\hline$A 4 V$ & 저주파 계수 행렬의 특징 파라미터(수직방향) \\
\hline$H 4 H$ & 고주파 계수 행렬의 특징 파라미터(수평방향) \\
\hline$H 4 V$ & 고주파 계수 행렬의 특징 파라미터(수직방향) \\
\hline D4H & 대각 고주파 계수 행렬의 특징 파라미터(수평방향) \\
\hline D4V & 대각 고주파 계수 행렬의 특징 파라미터(수직방향) \\
\hline
\end{tabular}

관전압 변화에 따라 얻어진 영상을 3레벨 DWT한 후 저주파영역에서 얻어진 Table 14의 파라미터 별로 $\mathrm{CR}$ 과 $\mathrm{DR}$ 의 관전압과 산란선의 상관관계를 알아보았다.

Fig. 4는 CR장치를 이용하여 획득한 영상을 3레벨 DWT한 것에서 저주파 계수 행렬의 특징 파라미터(수 평방향)를 $\mathrm{kVp}$ 변화에 따라 나타낸 그림이다. $\mathrm{kVp}$ 변 화에 따른 산란선의 변화가 있는 것으로 나타났다.

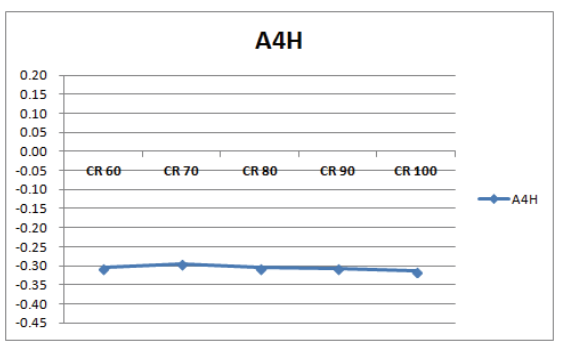

Fig. 4. Graph of average value in $\mathrm{A} 4 \mathrm{H}$ according to changed $\mathrm{kVp}$.

Fig. 5는 CR장치를 이용하여 획득한 영상을 3레벨 DWT한 것에서 저주파 계수 행렬의 특징 파라미터 (수직방향)를 $\mathrm{kVp}$ 변화에 따라 나타낸 그림이다. $[\mathrm{kVp}$ 가 높아질수록 산란선의 변화가 나타났다.

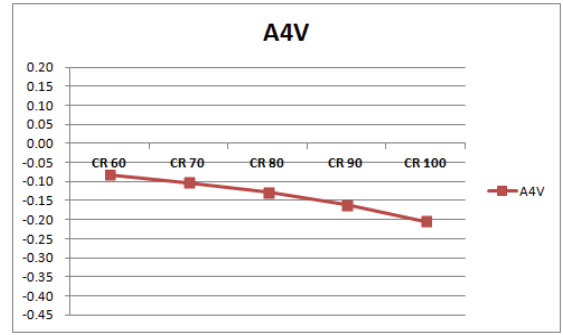

Fig. 5. Graph of average value in A4V according to changed $\mathrm{kVp}$.

Fig. 6은 CR장치를 이용하여 획득한 영상을 3레벨 $\mathrm{DWT}$ 한 것에서 수평 고주파 영역의 특징을 한 것으로 수평 고주파 계수 행렬의 특징 파라미터를 $\mathrm{kVp}$ 변화 에 따라 나타낸 그림이다.80 $\mathrm{kVp}$ 근방에서 산란선 의 급격한 변화가 나타났다.

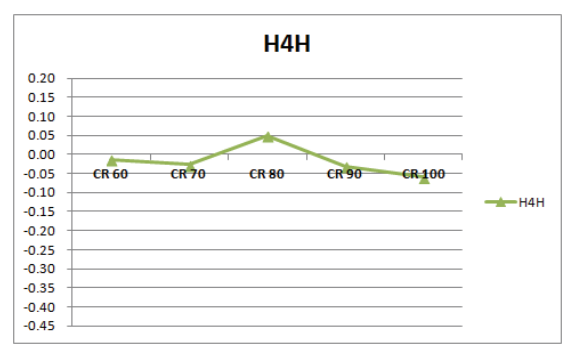

Fig. 6. Graph of average value in $\mathrm{H} 4 \mathrm{H}$ according to changed $\mathrm{kVp}$.

Fig. 7은 CR장치를 이용하여 획득한 영상을 3레벨 $\mathrm{DWT}$ 한 것에서 고주파영역의 특징을 추출한 것으로 수직 고주파 계수 행렬의 특징 파라미터를 $\mathrm{kVp}$ 변화 에 따라 나타낸 그림이다. $\mathrm{kVp}$ 가 높아질수록 산란선의 변화가 나타났다.

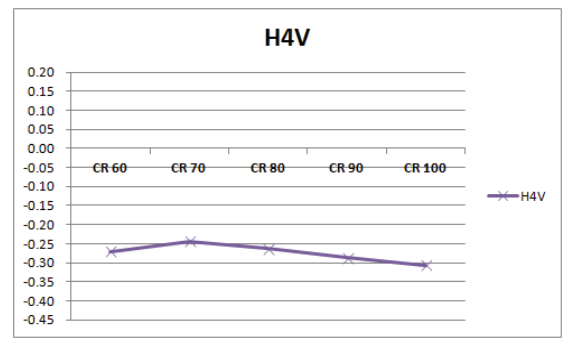

Fig. 7. Graph of average value in $\mathrm{H} 4 \mathrm{~V}$ according to changed $\mathrm{kVp}$

Fig. 8는 CR장치를 이용하여 획득한 영상을 3레벨 $\mathrm{DWT}$ 한 것에서 대각 고주파 영역의 특징을 한 것으로 수평 대각 고주파 계수 행렬의 특징 파라미터를 $\mathrm{kVp}$ 
변화에 따라 나타낸 그림이다. $80 \mathrm{kVp}$ 에서 산란선의 급격한 변화가 나타났다.

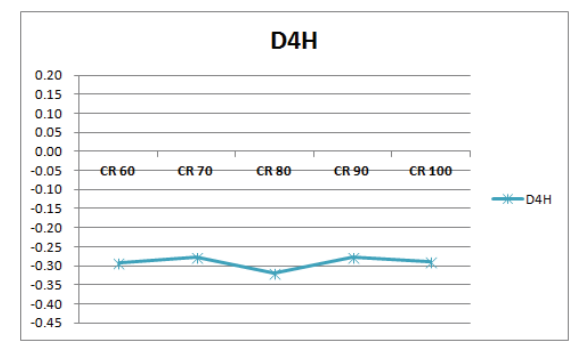

Fig. 8. Graph of average value in $\mathrm{D} 4 \mathrm{H}$ according to changed $\mathrm{kVp}$.

Fig. 9은 CR장치를 이용하여 획득한 영상을 3 레벨 DWT한 것에서 대각 고주파영역의 특징을 추출한 것 으로 수직 대각 고주파 계수 행렬의 특징 파라미터를 $\mathrm{kVp}$ 변화에 따라 나타낸 그림이다. $\mathrm{kVp}$ 변화에 따라 변화가 나타났다.

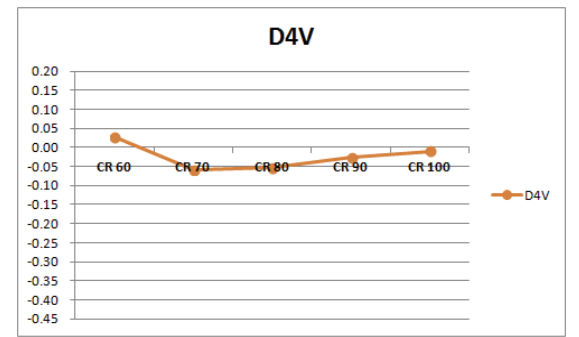

Fig. 9. Graph of average value in D4V according to changed $\mathrm{kVp}$.

\subsubsection{DR(Direct Radiography)}

Fig. 10은 DR장치를 이용하여 획득한 영상을 3 레 벨 DWT한 것에서 저주파 계수 행렬의 특징 파라미터 (수평방향)를 $\mathrm{kVp}$ 변화에 따라 나타낸 그림이다. $\mathrm{kVp}$ 변 화에 따른 산란선의 변화는 있는 것으로 나타났다.

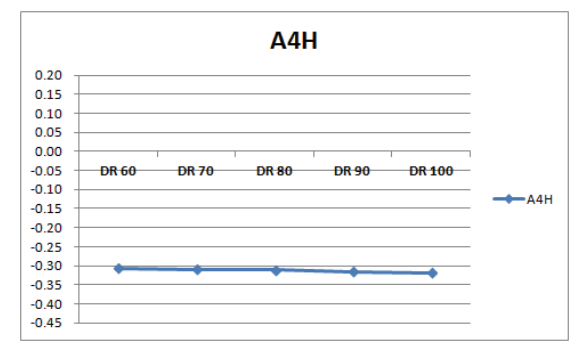

Fig. 10. Graph of average value in $\mathrm{A} 4 \mathrm{H}$ according to changed $\mathrm{kVp}$.
Fig. 11는 DR장치를 이용하여 획득한 영상을 3 레벨 $\mathrm{DWT}$ 한 것에서 저주파 계수 행렬의 특징 파라미터(수 직방향)를 $\mathrm{kVp}$ 변화에 따라 나타낸 그림이다. $\mathrm{kVp}$ 가 높 아질수록 산란선의 변화가 나타났다.

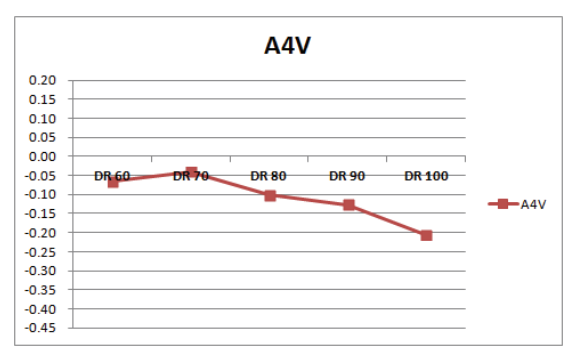

Fig. 11. Graph of average value in A4V according to changed $\mathrm{kVp}$.

Fig. 12 은 DR장치를 이용하여 획득한 영상을 3 레벨 $\mathrm{DWT}$ 한 것에서 고주파영역의 특징을 추출한 것으로 수평 고주파 계수 행렬의 특징 파라미터를 $\mathrm{kVp}$ 변화에 따라 나타낸 그림이다. $80 \sim 90 \mathrm{kVp}$ 근방에서 산란선 의 급격한 변화가 나타났다.

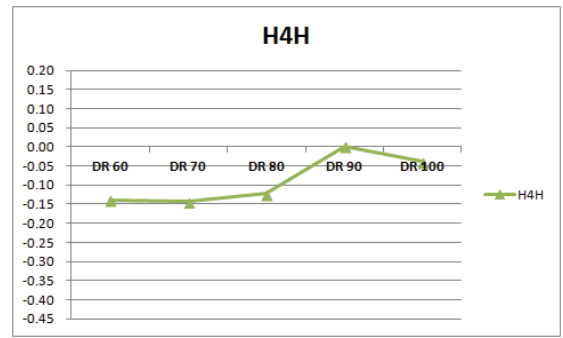

Fig. 12. Graph of average value in $\mathrm{H} 4 \mathrm{H}$ according to changed $\mathrm{kVp}$.

Fig. 13은 DR장치를 이용하여 획득한 영상을 3 레벨 DWT한 것에서 수직 고주파 계수 행렬의 특징 파라미 터를 $\mathrm{kVp}$ 변화에 따라 나타낸 그림이다. $\mathrm{kVp}$ 변화에 따른 산란선 변화는 있는 것으로 나타났다.

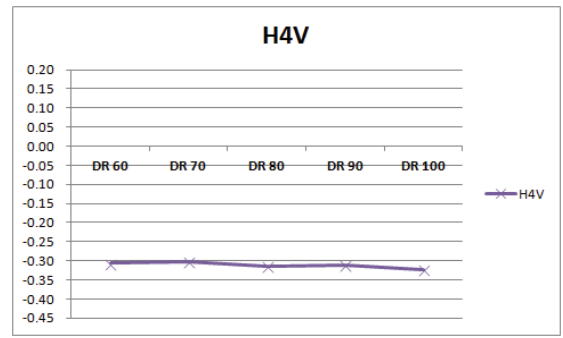

Fig. 13. Graph of average value in H4V according to changed $k \mathrm{p}$. 
Fig. 14은 DR장치를 이용하여 획득한 영상을 3레벨 DWT한 것에서 수평 대각 고주파 계수 행렬의 특징 파라미터를 $\mathrm{kVp}$ 변화에 따라 나타낸 그림이다. $90 \mathrm{kVp}$ $\sim 100 \mathrm{kVp}$ 에서 산란선의 급격한 변화가 나타났다.

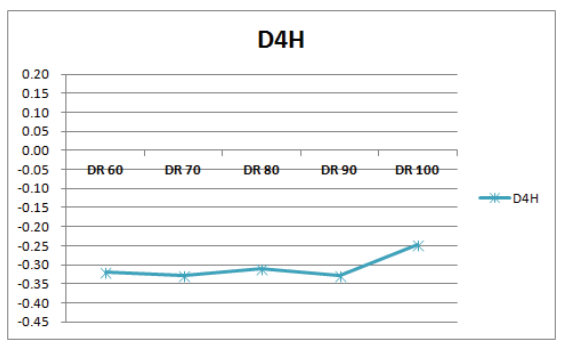

Fig. 14. Graph of average value in $\mathrm{D} 4 \mathrm{H}$ according to changed $\mathrm{kVp}$.

Fig. 15은 DR장치를 이용하여 획득한 영상을 3레벨 $\mathrm{DWT}$ 한 것에서 수직 대각 고주파 계수 행렬의 특징 파라미터를 $\mathrm{kVp}$ 변화에 따라 나타낸 그림이다. $90 \mathrm{kVp}$ $\sim 100 \mathrm{kVp}$ 에서 급격한 변화가 나타났다.

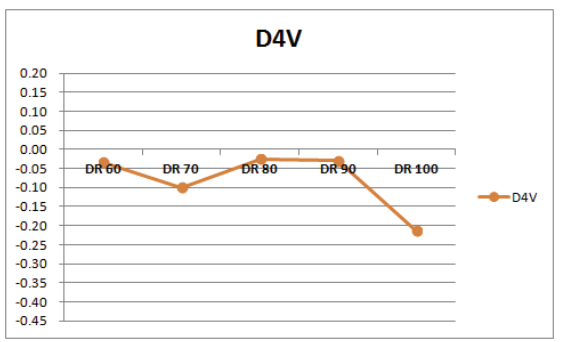

Fig. 15. Graph of average value in D4V according to changed $\mathrm{kVp}$.

\section{$\mathrm{IV}$. 고 찰}

방사선을 의학영상에 이용하는 것은 방사선과 물질 과의 상호작용에서 일어나는 전리 현상을 이용하는 것으로 진단영역에서는 전자기파(광자)와 물질과의 상 호작용이 주로 사용되며, 전자기파(광자)와 물질과의 상호작용은 엑스선, 감마선과 물질과의 상호작용이라 할 수 있다. 의학영상에서 이용하는 방사선의 에너지 대역은 $40 \sim 150 \mathrm{kVp}$ 를 사용하고 있다[Fig. 16].

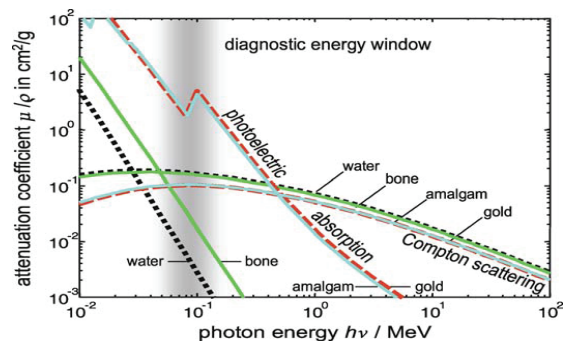

Fig. 16. Photoelectric Effect, Compton Scattering.

이러한 에너지 대역에서는 발생하는 방사선과 물질 과의 상호작용은 광전효과와 Compton 산란이 일어난 다. 광전효과는 입사 광자가 완전히 소멸하면서 충돌 에 의하여 궤도를 이탈한 광전자만 수광체에 도달함 으로 영상형성에 도움이 되지만, Compton 산란은 입 사 광자와 Compton 전자가 동시에 수광체에 도달하게 되어 영상을 왜곡되게 한다. 방사선진단 시 발생되는 대부분의 산란선은 Compton 산란에 의한 것이다. 본 연구에서는 관전압의 증가에 의하여 발생하는 Compton 산란이 화질에 영향을 미친다는 가설을 증명 하기 위하여 웨이브렛 변환으로 신호의 특성을 추출 하고, 추출된 데이터를 분석하여 관전압의 변화에 따 른 산란선의 화질영향 정도를 평가하고자 하였다. 실 험에 필요한 영상을 획득하기 위하여 아크릴 판위에 크기를 각각 다르게 홈을 파서 파라핀과 황산바륨 $\left(\mathrm{BaSO}_{4}\right)$ 으로 구멍을 채워 넣은 시료를 만들었으며, $\mathrm{CR}$ 과 $\mathrm{DR}$ 장비를 이용하여 시료의 영상을 획득하였다. 획 득된 영상을 3 레벨 DWT 분해한 후 저주파영역의 특 징을 추출하였다. 추출한 파라미터( $\mathrm{A} 4 \mathrm{H}, \mathrm{A} 4 \mathrm{~V}, \mathrm{H} 4 \mathrm{H}$, $\mathrm{H} 4 \mathrm{~V}, \mathrm{D} 4 \mathrm{H}, \mathrm{D} 4 \mathrm{~V}$ )들을 각각 평균값을 구하여 $\mathrm{kVp}$ 변화 에 따른 산란선의 영향을 평가하였다. 평가결과 $\mathrm{CR}$ 과 $\mathrm{DR}$ 에서 $\mathrm{kVp}$ 변화에 따른 산란선의 영향은 거의 유사 하게 나타났으며, CR과 DR 모두 관전압 변화에 따라 서 고주파영역의 주파수의 변화가 있는 것으로 보아 Compton 산란선 영향이 있는 것으로 나타났다. $\mathrm{H} 4 \mathrm{H}$ (수평고주파)영역에서 $\mathrm{CR}$ 의 경우 $80 \mathrm{kVp}$ 영역에서, $\mathrm{DR}$ 의 경우 $90 \mathrm{kVp}$ 영역에서 주파수 변화가 급격하게 일 어나는 현상이 발생하는 것은 광전효과에 의한 광전 자와 Compton 산란에 의한 Compton 전자, 그리고 Compton 산란선이 동시에 수광체에 영향을 미친 것으 로 나타났다. 공학용 도구인 MatLab Tool을 이용한 영 
상의 화질평가 방법이 앞으로 화질의 평가를 할 수 있 는 Tool로 유용하게 적용되리라 사료된다.

\section{$\mathrm{V}$. 결 론}

본 연구에서는 관전압의 증가에 의하여 발생하는 산란선(Compton 산란)이 화질에 영향을 미친다는 가 설을 증명하기 위하여 공학용 도구인 MatLab Tool을 이용하여 프로그램을 작성하고 이를 이용하여 관전압 증가에 따른 산란선의 변화를 평가하였다. 영역별 평 가 결과는 다음과 같았다.

수평 저주파영역에서는 $\mathrm{kVp}$ 변화에 따른 산란선의 변화는 있는 것으로 나타났으며, 수직 저주파영역에서 는 $\mathrm{kVp}$ 가 높아질수록 산란선의 변화가 나타났다. 수평 고주파영역에서는 $\mathrm{CR}$ 의 경우 $80 \mathrm{kVp}$ 근방에서 급격한 산란선 변화가 나타났으며, DR의 경우 $80 \sim 90 \mathrm{kVp}$ 근방에서 급격한 산란선 변화가 나타났다. 수직 고주 파영역에서는 $\mathrm{CR}$ 의 경우 $\mathrm{kVp}$ 가 높아질수록 산란선의 변화가 나타났으며, $\mathrm{DR}$ 의 경우 $\mathrm{kVp}$ 변화에 따른 산란 선의 변화가 나타났다. 수평 대각 고주파영역에서는 $\mathrm{CR}$ 의 경우 $80 \mathrm{kVp}$ 에서 산란선의 급격한 변화가 나타 났으며, $\mathrm{DR}$ 의 경우 $100 \mathrm{kVp}$ 에서 산란선의 변화가 나 타났다. 수직 대각 고주파영역에서는 $\mathrm{CR}$ 의 경우 $\mathrm{kVp}$ 변화에 따라 변화가 나타났으며, $\mathrm{DR}$ 의 경우 $100 \mathrm{kVp}$ 에서 변화가 나타났다. 평가 결과 다음과 같은 연구 결과를 얻을 수 있었다. 첫째, $\mathrm{CR}$ 과 $\mathrm{DR}$ 모두 관전압 변화에 따라서 고주파영역의 주파수의 변화가 있는 것으로 보아 Compton 산란선 영향이 있는 것으로 나 타났다. 둘째, 수평 고주파영역에서 $\mathrm{CR}$ 의 경우 $80 \mathrm{kVp}$ 영역에서, $\mathrm{DR}$ 의 경우 $90 \mathrm{kVp}$ 영역에서 주파수 변화가 급격하게 일어나는 현상이 발생하는 것은 광전효과에 의한 광전자와 Compton 산란에 의한 Compton 전자, 그리고 Compton 산란선이 동시에 수광체에 영향을 미 친 것으로 나타났다. 셋째, 이 현상에서 급격한 주파 수의 변화가 나타나는 관전압 영역이 $\mathrm{CR}$ 은 $80 \mathrm{kVp}$, $\mathrm{DR}$ 은 $90 \mathrm{kVp}$ 로 나타난 것으로 보아 $\mathrm{DR}$ 의 수광체 민 감도가 낮은 것으로 판단된다. 결론적으로 본 연구의 결과로 보아 CR보다는 $\mathrm{DR}$ 이 에너지가 높은 방사선에 민감한 것으로 나타났다, 이 결과는 $\mathrm{DR}$ 장치로 촬영 을 할 때 촬영 조건을 높게(방사선의 강도를 높게)하
여야 하는 것으로 판단된다. 촬영 조건을 높게 하여 촬영을 한다면 국민전체의 피폭선량이 증가하게 되는 문제가 발생한다. 따라서 점진적으로 $\mathrm{DR}$ 환경으로 변 하고 있는 현 임상현장의 실태로 보아 DR 수광체에 대한 연구가 진전되어야 할 것으로 사료된다.

\section{참 고 문 헌}

[1] Changho Kim, Seunghum Yu, Sunhee Lee, Tae Yongs, Factors Affecting Job Satisfaction among the Radiologic Technologists, Korean Society of Radiological Science, Vol. 20, No. 1, pp. 77-83, 1997.

[2] Sunyoup Lee, A study on the safety management of diagnostic radiation devices, yonsei Uni., 1997.

[3] Ministry of Health and Welfare, Statistical Yearbook of Health and Social, 1994.

[4] Kyung Hee Moon, Study on the contractibility of isolated Goldfish Interstines exposed to the $18 \mathrm{~F}$ isotope, Department of Physics, The Graduate School Pukyong National University, pp. $1-42,2007$.

[5] Joo Yul Park, Applications of Radioactivity Detector Systems in Undergraduate Modern Physics Experimental Education, Graduate School of Korea National Unversity of Education Chung-Buk, KOREA, pp. 3, 2005.

[6] Kyung Hee Moon, Study on the contractibility of isolated Goldfish Interstines exposed to the $18 \mathrm{~F}$ isotope, Department of Physics, The Graduate School Pukyong National University, pp. $1-42,2007$.

[7] Jonghyo Kim, Taesoo Lee, Kwangsuk Park, Mancheong Han, Choongwoong Lee, \& Byounggoo Min, Characterization of Imaging and Physical Properties in Digital Radiography System. The Institute Of Electronics Engineers Of Korea, Vol. 26, No. 7, pp. 1064-1076, 1989.

[8] Carla D. Bradford, Walter W. Peppler, Performance characteristics of a Kodak computed radiography system, Med. Phys., Vol. 26, pp. 27-37, 1999.

[9] Ehsan Samei, Michael J. Flynn, Harrell G. Chotas, James T., Dobbins III, DQE of direct and indirect digital radiography systems, Proceedings of SPIE, 4320, pp. 189-197, 2001.

[10] Daesung Pack, Guirack Choi, Byungsung Han, Byungju Ahn, Feature values of DWT using MR general imaging and molecular imaging, Journal of the Korean Society of Radiology, Vol. 6, No. 5, pp. 409-414 2012. 